\title{
Neurobehavioural Correlates of Abnormal Repetitive Behaviour
}

\author{
R. A. FORD \\ Springfield Hospital Glenburnie Road, London SW17, UK \\ Correspondence to: Warlingham Park Hospital, Warlingham, Surrey CR3 9YR, UK
}

\begin{abstract}
Conditions in which echolalia and echopraxia occur are reviewed, followed by an attempt to elicit possible mechanisms of these phenomena. A brief description of stereotypical and perseverative behaviour and obsessional phenomena is given. It is suggested that abnormal repetitive behaviour may occur partly as a result of central dopaminergic dysfunction.
\end{abstract}

\section{Introduction}

Repetition of the motor activities or language of another person is usually under voluntary control; if it becomes an involuntary process it may be indicative of an underlying disease process. Echophenomena is a term which encompasses echolalia and echopraxia. Echolalia is the repetition of another individual's speech, and does not usually serve a communicative purpose. Echopraxia is the repetition of another individual's motor activities, and is usually non-goal-directed. Echolalia is found in conditions in which there is an abnormality or immaturity of communicative processes, such as in acquired deafness, during normal childhood speech development, transcortical aphasias and childhood autism. Echolalia and echopraxia are frequently found together in conditions such as catatonia, Gilles de la Tourette syndrome and the hyperekplexias. Other phenomena characterized by an excessive tendency to repetition are mannerisms, stereotyped behaviour and perseveration. Stereotyped behaviour has been defined as repetitive, nongoal-directed actions which are carried out in a uniform way. If the particular behaviour is thought to be goal-directed, it is classified as a mannerism (Fish, 1974), although the distinction between the two is an artificial one. Perseverative behaviour has been defined as that which tends to persist beyond the point at which it is relevant (Fish, 1974). Obsessional phenomena originate from repeated obsessional thoughts which intrude into consciousness, and may result in repeated motor acts such as compulsions and rituals.

\section{Conditions Associated with Echophenomena}

Echophenomena are a wide range of psychopathology found in disorders from purely neurological syndromes to strongly socially conditioned behaviour. Echoing is an idiosyncratic response to a stimulus, the chain of 
events from stimulus to motor act may be examined to elucidate possible mechanisms.

Echolalia is a feature of the transcortical aphasias. The tendency to produce echolalic responses is strongest in transcortical sensory aphasia (Benson, 1979) and is then frequently associated with completion phenomena (Stengel, 1947) in which the subject completes the examiner's unfinished phrases. There is a weaker tendency to produce echolalic utterances in transcortical motor aphasia, and an intermediate tendency in mixed transcortical aphasia. During the process of recovery from transcortical aphasia, echolalic utterances decrease in frequency and undergo a transition from an automatic or involuntary type to a mitigated or voluntary type. In automatic echolalia the subject has a degree of control over the echoed utterances and is able to suppress them if required (Stengel, 1947). Echolalia is the commonest abnormality found in the speech of the minority of autistic children who develop spoken language (Rutter, 1966); however the echolalia is only one aspect of a more generalized disturbance of inner language and cognitive impairment (Rutter, 1985). Although echolalia is not usually thought of as serving a communicative function, autistic echolalia may acquire some idiosyncratic, symbolic meaning (Howlin, 1980). The stress, pitch and intonation of autistic speech are abnormal (Simon, 1975) and autistic echolalic utterances frequently have pronomial reversal. The autistic child cannot extract essential morphemic components from the speech of others, but repeats the whole phrase in a parrot-like manner, as if there were no grasp of the meaning of the echoed utterance.

Delayed echolalia, an unusual phenomenon, unique to autism, is characterized by an echolalic utterance occurring after an interval following the stimulus phrase; the interval may be minutes, hours, days or weeks. Fay and Schuler (1980) suggested that delayed echolalia may be internally triggered, perhaps by mental imagery or conditioning and that the more immediate type is externally triggered by the speech of others. Delayed echolalia, however, appears to fulfil more adequately the criteria for perseveration than echolalia. Developmental echolalia is a phenomenon in the speech of normal children, from as young as 8 months of age. Persistent echolalia after 3 years of age is always abnormal. In contrast to autistic echolalia, the developmental type is often not a literal repetition of the stimulus phrase as inflection and function words are often omitted (Schlesinger, 1975), pronomial reversal does not occur and developmental echolalia is of a mitigated type.

Echolalia and echopraxia may be found together in the hyperekplexias, the Tourette syndrome and in catatonia. In the Tourette syndrome, echolalia occurs with a reported prevalence of between $17 \cdot 6 \%$ (Shapiro et al., 1988) and $46 \%$ (Less et al., 1984) of cases. As a feature of Tourettism, echolalia is an example of a complex vocal tic (American Psychiatric Association, 1987), a tic being defined as an involuntary, sudden, rapid, recurrent, non-rhythmic, stereotyped motor movement or vocalisation. Shapiro et al. (1988) also described the phenomenon of so-called "mental echoing", which was not accompanied by a motor component. Echopraxia 
occurs less frequently than echolalia, from $8.4 \%$ (Shapiro et al., 1988) to $21 \%$ (Lees et al., 1984) of cases. The mean age of onset of echophenomena in Tourettism is at about the same time as that for coprolalia, in early adolescence (Lees et al., 1984). Echolalia and echopraxia also coexist in catatonia, and may be found in association with other bizarre disorders of posture, muscle tone and motor control. Functional psychiatric disorders and organic illnesses can result in catatonia, and there may be similarities between these disorders and the occasional development of echolalia in normal individuals during states of fatigue impaired concentration and waking from sleep. Echolalia and echopraxia have also been described in the hyperekplexias, of which the most well known examples are the Jumping Frenchmen of Maine (Beard, 1880) and Latah (O'Brien, 1883). These conditions remain very poorly understood.

\section{Possible Mechanisms of Echophenomena}

An echoed response is more likely to follow a complex or unfamiliar stimulus than a simple or novel one. This has been found in developmental echolalia (Prutting and Connolly, 1976) and autistic echolalia (Schreibman and Carr, 1978). Stengel (1947) found that echolalia was more likely to occur when comprehension was impaired and was then frequently found in association with completion phenomena. The strong tendency to produce echolalic responses in transcortical sensory aphasia occurs in the context of very impaired receptive language and relative sparing of expressive language, and even nonsense or foreign phrases may be echoed (Benson, 1979). Prutting and Connolly (1976) noted that the frequency of developmental echolalic responses decreased as linguistic ability increased. Similarly, Howlin (1982) found that the incidence of echolalia was reduced in autistic children of more advanced linguistic ability.

Primitive neurological signs such as grasp, rooting, sucking and palmomental reflexes are examples of so-called release phenomena and are frequently found in frontal lobe damage, although Stuss and Benson (1985) claim that diencephalic lesions are more often responsible for there signs. Schneider (1938) described a collection of clinical features which included sucking and grasp reflexes together with echolalia and echopraxia, which he suggested may be a manifestation of widespread brain disease or of lesions of the pre-motor frontal cortex. This would indicate that the echophenomena associated with organic brain disease are also examples of release phenomena and may represent examples of primitive reflexes. This would imply that some of the social behaviours observed during infancy are examples of echophenomena, and may reappear in later life due to a process of neurological disinhibition.

In catatonia, extreme variations of behaviour may coexist, ranging from negativism to features such as automatic obedience, waxy flexibility, mitmachen, mitgehen, echolalia and echopraxia. Affective disorders and organic illnesses are more common causes of catatonia than schizophrenia (Gelenberg, 1976; Abrams and Taylor, 1976), although historically catato- 
nia has been strongly associated with schizophrenia. Andreasen (1986) included echolalia as an uncommon variety of formal thought disorder. Using ideas adopted from association psychology, Bleuler (1950) saw echopraxia in schizophrenia as a sign of associative loosening. Impaired information processing has been an extensively studied model of psychopathology in schizophrenia, e.g. Broadbent (1958), Chapman and McGhie (1964) and Helmsley (1975). It is therefore possible to speculate that several possible mechanisms may be responsible for echophenomena, and the wide range of other psychopathology found in catatonia, including disinhibition of primitive reflexes, sensory cognitive impairment, delusions of control and dopaminergic overactivity. There is substantial evidence that other motor disorders which may result in echophenomena are associated with central dopaminergic dysfunction. Anti-dopaminergic drugs successfully reduce the severity of tics in the Tourette syndrome (Shapiro et al., 1988); symptomatic Tourettism has been described following D-amphetamine usage (Lowo $e t$ al., 1982); L-dopa (Klemple, 1974) and following epidemic encephalitis lethargica (Wilder and Silbermann 1927). So-called tardive Tourettism has been described following long-term administration of neuroleptic drugs and following their withdrawal (Klawans et al., 1978; Fog and Pakkenberg 1981). Echophenomena are also a feature of the hyperekplexias, and it is interesting to note that dopaminergic drugs increase startle-response amplitude (Kokkinidis and McNeil, 1982).

\section{Other Repetitive Phenomena}

Ridley and Baker (1982) classify stereotyped movements into (i) those arising from constraint, so-called cage stereotypes; (ii) those associated with social and sensory deprivation in infancy; (iii) movements precipated by stimulant drugs such as amphetamines; and (iv) sterotypies found in developmental disorders such as childhood autism, congenital blindness and stereotypies found in adult psychotic disorders. Stereotyped behaviour may have a recognized precipitant and is subject to considerable environmental modification. Mumford et al. (1979) observed that amphetamine treated rats exhibit more stereotyped behaviour in a familiar environment. Lyon and Robbins (1975) hypothesized that amphetamine-induced stereotypies result from increased competition amongst a narrowing response repertoire, resulting in the repetitive performance of out-of-context motor elements. Teitelbaum et al. (1990) concluded that stereotypical behaviour results from a hierarchical disintegration of behaviour. There is evidence from experimental animals to suggest that stereotyped behaviour is mediated mainly by ascending dopaminergic pathways in the corpus striatum and possibly in the pre-frontal cortex (Robbins et al., 1990).

Perseveration is characterized by "... the continuation or recurrence of a purposeful response which is more appropriate to a preceding stimulus than to the succeeding one which has just been given and which is essential to provoke it" (Allison, 1966). Allison (1966) concluded that it could not be 
localized to any specific brain area, but used a wider definition of the term than is usual to include perseverative sensory phenomena, as did Critchley (1953). Luria (1965) classified perseverative responses into two types (i) an efferent type, characterized by the repeated occurrence of the response, and (ii) that in which a response which is elicited under an initial stimulus continues when a second stimulus is presented, and is characterized by impaired switching from one action to another. The former was thought to be more common with subcortical frontal lobe and basal ganglia pathology and the latter associated with posteriorly situated frontal lesions. Allison (1966) found perseverative responses in 16 out of 24 subjects with aphasia. Freeman and Gathercole (1966) found no difference in the rate of perseverative responses when comparing subjects with dementia and those with chronic schizophrenia. Allison (1966) concluded that in clinical practice, perseverative responses occur most often in states of clouded consciousness, Pick's disease, Alzheimer's disease, vascular lesions and neoplasia. Perseverative responses and stereotypies can also occur as part of normal behaviour.

Obsessional phenomena are examples of repetitive behaviour, which may or may not be pathological. There is evidence that obsessive-compulsive behaviour is associated with basal ganglia pathology. Von Economo (1931) described a sense of compulsion of thought and action in post-encephalitic Parkinsonism and also described a variety of motor and vocal tics. The other condition associated with basal ganglia pathology and in which obsessional phenomena are common is the Tourette syndrome. Numerous case-reports and large-scale studies have found a strong link between the two (Robertson 1989). Robertson et al. (1988) found that $37 \%$ of 90 subjects with the Tourette syndrome reported obsessive-compulsive behaviour, which interestingly was associated with the occurrence of coprolalia and echophenomena.

\section{Conclusion}

Inappropriate repetitive responses occur in normal behaviour as well as in a wide variety of brain disorders. Echolalia can occur as a manifestation of linguistic impairment, such as in acquired deafness or transcortical aphasia in which there is a sensory/receptive impairment of language; in normal childhood speech in which there is an immaturity of language development; and in childhood autism in which there appears to be a dysmaturity of language development. Echolalia and echopraxia may be manifestations of a motor neurological disorder such as hyperekplexia, tic disorders and catatonia. In these examples there may be an association with central dopaminergic overactivity. Organic brain disease may also result in echolalia or echopraxia through a process of disinhibition of primitive reflexes.

Other examples of abnormal repetitive behaviour include stereotypies, mannerisms, perseveration and obsessional phenomena. Current evidence suggests that stereotypical behaviour may be mediated by ascending dopaminergic pathways, but is subject to environmental modification. Perseveration has been defined in various ways, but contemporary usage is mostly 
confined to repeated inappropriate motor responses which are usually found in association with lesions of the frontal lobes. Obsessional phenomena may be found in association with basal ganglia disorders in conditions thought to be associated with abnormal dopaminergic activity. There is therefore much direct and indirect evidence to suggest that abnormal repetitive behaviour occurs as a result of central dopaminergic dysfunction due to basal ganglia and frontal lobe pathology.

\section{References}

Abrams, R. and Taylor, M. B. (1976). Catatonia-a prospective clinical study. Archives of General Psychiatry, 33, 579-581.

Allison, R.S. (1966). Perseveration as a sign of diffuse and focal brain damage. British Medical Fournal, 2, 1027-1032 and 1095-1101.

American Psychiatric Association (1987). Diagnostic and Statistical Manual of Mental Disorders, (3rd Edition, revised); (DSM-III-R) Washington DC.

Andreasen, N. C. (1986). Scale for the assessment of thought, language and communication. Schizophrenia Bulletin, 12, 473-482.

Beard, G. (1880). Experiments with the jumpers and jumping Frenchmen of Maine. Fournal of Nervous and Mental Disease, 7, 487-490.

Benson, D. F. (1979). "Asphasia, Alexia and Agraphia". Churchill Livingstone, London.

Bleuler, E. (1950). "Dementia Praecox or the Group of Schizophrenias". International University Press. New York.

Broadbent, D. E. (1958). "Perception and Communication". Pergamon, London.

Chapman, J. and McGhie, A. (1964). Echopraxia in schizophrenia. British fournal of Psychiatry, 110, 365-374.

Critchley, M. (1953). "The Parietal Lobes". Arnold, London.

Fay, W. H. and Schuler, A. L. (1980). "Emerging Language in Autistic Children". Edward Arnold, London.

Fish, F. (1974). "Fish's Clinical Psychopathology: Signs and Symptoms in Psychiatry". (Ed. M. Hamilton). John Wright, Bristol.

Fog, R. and Pakkenberg, H. (1981). Neuroleptic-induced tardive Tourette's syndrome and neurotoxicity. In "Clinical Pharmacology in Psychiatry". (Eds E. Urdin, S. Dahl, L. Grain and O. Linegarde). Macmillan. London.

Freeman, T. and Gathercole, C. E. (1966). Perseveration: the clinical symptoms in chronic schizophrenia and organic dementia. British Fournal of Psychiatry, 112, 27-32.

Gelenberg, A. J. (1976). The catatonic syndrome. Lancet, i, 1339-1341.

Helmsley, D. R. (1975). A two stage model of attention in schizophrenia research. British Journal of Social and Clinical Psychology, 14, 81-89.

Howlin, P. (1980). The home treatment of autistic children. In "Language and Language Disorders in Childhood". (Eds L. A. Hersov and M. Berger), pp. 115-145. Pergamon Press, New York.

Klawans, J. K., Falk, D. K., Naseida P. A. et al. (1978). Gilles de la Tourette Syndrome after long-term chlorpromazine therapy. Neurology, 28, 1064-1066.

Klemple, K. (1974). Gilles de la Tourette Symptoms induced by levodopa. South African Medical Journal, 48, 1379-1380.

Kokkinidis, L. and McNeil, S. P. (1982). Potentiation of d-amphetamine and L-dopa induced acoustic startle activity after long-term exposure to amphetamine. Psychopharmacology, 78, 331-335.

Lees, A. J., Robertson, M., Trimble, M. R. et al. (1984). A clinical study of Gilles de la Tourette syndrome in the United Kingdom. Fournal of Neurology, Neurosurgery and Psychiatry, 47, 1-8.

Lowo, T. L. J., Cohen, J., Detlor, M. W. et al. (1982). Stimulant medications precipitate Tourette's syndrome. Fournal of the American Medical Association, 247, 1729-1731. 
Luria, A. R. (1965). Two kinds of motor perseveration in massive injury of the frontal lobes. Brain, 88, 1-10.

Mumford, L., Teixeira, A. R. and Kumar, R. (1979). Sources of variation in locomotor activity and stereotyping in rats treated with D-amphetamine. Psychopharmacology, 62, 241-245.

O'Brien, J. A. (1883) Latah. Journal of the Straits Branch of the Royal Asiatic Society, 11, 143-153.

Prutting, C. A. and Connolly, J. E. (1976). Imitation: a closer look. Journal of Speech and Hearing Disorders, 41, 412-422.

Ridley, R. M. and Baker, H. F. (1982). Stereotypy in monkeys and humans. Psychological Medicine, 12, 61-72.

Robertson, M. M. (1989). The Gilles de la Tourette Syndrome. The current status. British Journal of Psychiatry, 154, 147-169.

Robertson, M., Trimble, M. R. and Lees, A. J. (1988). The psychopathology of the Gilles de la Tourette syndrome: a phenomenological analysis. British Journal of Psychiatry, 152, 383-390.

Robbins, T. W., Mittleman, G., O'Brien, J. et al. (1990). The neuropsychological significance of stereotypy induced by stimulant drugs. In "Neurobiology of Stereotyped Behaviour". (Eds S. J. Cooper and C. T. Dourish), pp. 25 63. Clarendon Press, Oxford.

Rutter. M. (1966). Behavioural and cognitive characteristics of a series of psychotic children. In "Early Childhood Autism-Clinical, Educational and Social Aspects". (Ed. J. K. Wing), pp. 51-81. Pergamon Press, London.

Rutter, M. (1985). Infantile autism and other pervasive development disorders. In "Child and Adolescent Psychiatry-Modern Approaches", 2nd Edn (Ed. M. Rutter and L. Hersov). pp. 545-566. Blackwell, Oxford.

Schlesinger, I. M. (1975). Grammatical development-the first steps. In "Foundations of Language Development--a Multi-disciplinary Approach, Vol. 1. (Eds E. H. Lennenberg and E. Lennenberg), pp. 203-222. Academic Press.

Schneider, D. E. (1938). The clinical syndromes of echolalia, echopraxia, grasping and sucking. Fournal of Nervous and Mental Disease, 88, 18-35, 200-216.

Schriebman, L. and Carr, E. G. (1978). Elimination of echolalic responding to questions through the training of a generalised verbal response. Fournal of Applied Behaviour Analysis, $11,453-463$.

Shapiro, A. K., Shapiro, E. S., Young, E. G. et al. (1988). "Gilles de la Tourette Syndrome" (2nd Edn) Raven Press, New York.

Simon, N. (1975). Echolalic speech in childhood autism. Archives of General Psychiatry, 32, $1439-1446$.

Stengel, E. (1947). A clinical and psychological study of echoreactions. Fournal of Mental Science, 93, 598-612.

Stuss, D. T. and Benson, D. F. (1985). "The Frontal Lobes". Raven Press, New York.

Teitelbaum, P., Pellis, S. M. and Devietti, T. L. (1990). Disintegration into stereotypy induced by drugs or brain damage: a microdescriptive behavioural analysis. In "Neurobiology of Stereotyped Behaviour". (Eds S. J. Cooper and C. T. Dourish), pp. 169-199. Clarendon Press, Oxford.

Von Economo, C. (1931). "Encephalitis lethargica, its Sequelae and Treatment". Translated by Newman K. O. Oxford University Press, London.

Wilder, J. and Silbermann, J. (1927). "Beitrage zum Tic Problem. Abhandlungen and der Neurologie Psychiatrie und ihren Grenzgebeteiten". Karger, Berlin. 


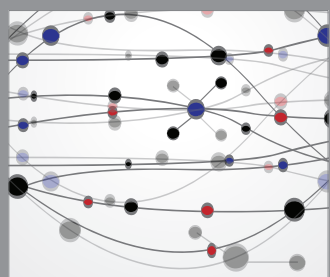

The Scientific World Journal
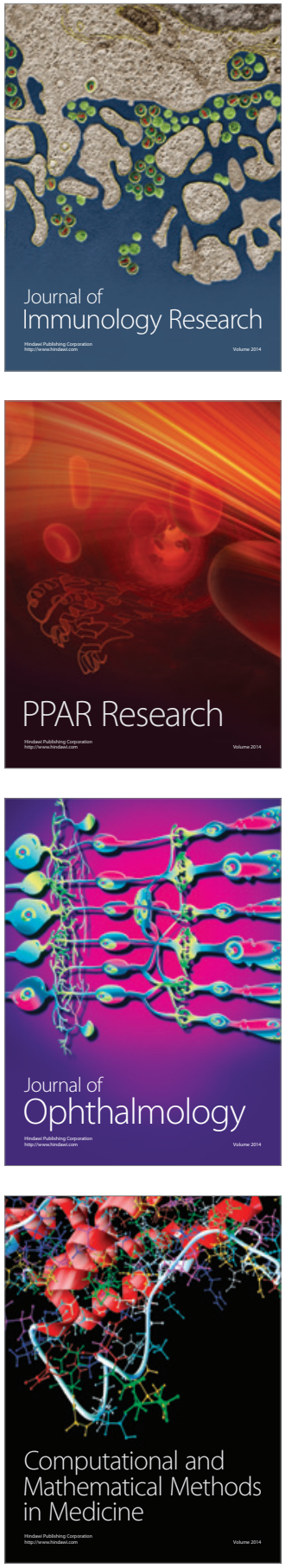

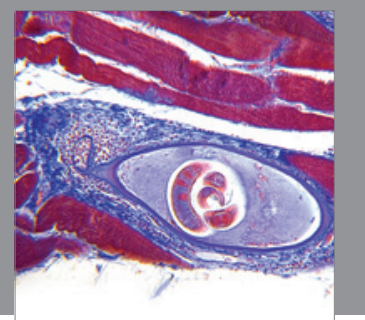

Gastroenterology

Research and Practice
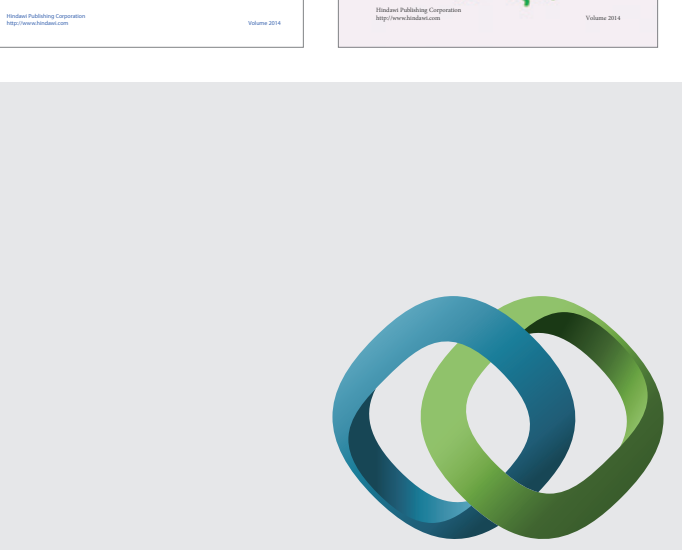

\section{Hindawi}

Submit your manuscripts at

http://www.hindawi.com
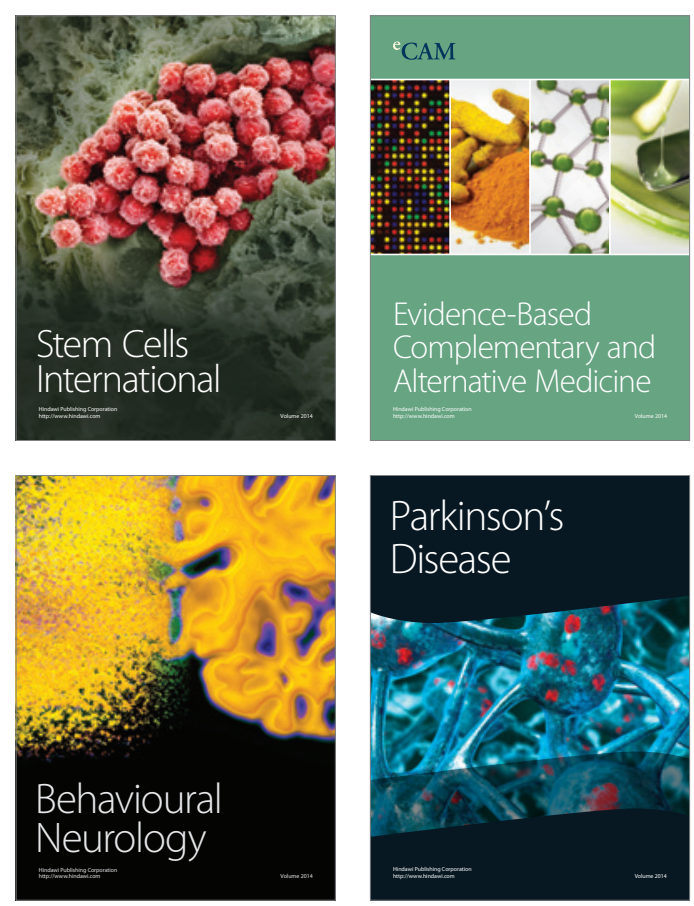

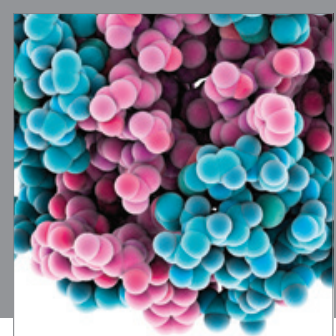

Journal of
Diabetes Research

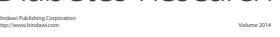

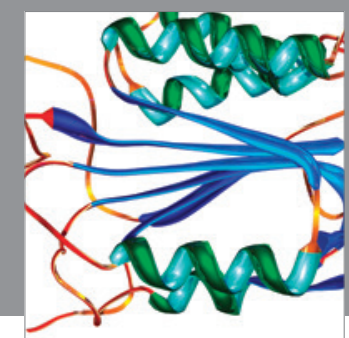

Disease Markers
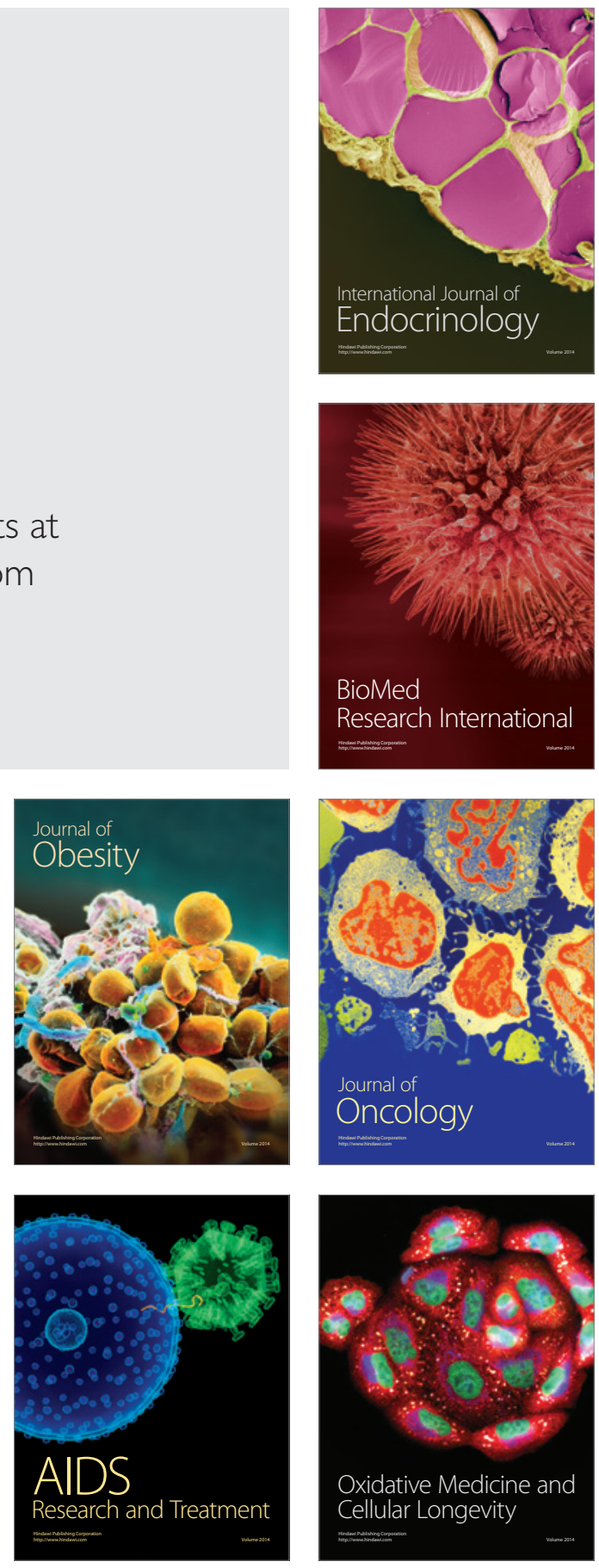